\title{
A Dimensioning and Tolerancing Methodology for Concurrent Engineering Applications II: Comprehensive Solution Strategy
}

\author{
M. N. ISLAM \\ Department of Mechanical Engineering, Curtin University of Technology, Perth, \\ WA 6845, Australia
}




\title{
A Dimensioning and Tolerancing Methodology for Concurrent Engineering Applications II: Comprehensive Solution Strategy
}

\begin{abstract}
Dimensioning and Tolerancing (D\&T) is a multidisciplinary problem which requires the fulfilment of a large number of dimensional requirements. However, almost all of the currently available D\&T tools are only intended for use by the designer. In addition, they typically provide solutions for the requirements one at time. This paper presents a methodology for determining the dimensional specifications of the component parts and sub-assemblies of a product by satisfying all of its requirements. The comprehensive solution strategy presented here includes: a strategy for separating D\&T problems into groups, the determination of an optimum solution order for coupled functional equations, a generic tolerance allocation strategy, and strategies for solving different types of D\&T problems. A number of commonly used cost minimization strategies, such as the use of standard parts, preferred sizes, preferred fits, and preferred tolerances, have also been incorporated into the proposed methodology. The methodology is interactive and intended for use in a Concurrent Engineering environment by members of a product development team.
\end{abstract}

Keywords: Dimensioning and Tolerancing, Concurrent Engineering, Preferred Size, Dimensional Specification 


\section{Introduction}

Determining the dimensional specifications of a product is an integral part of product design and necessitates the fulfilment of a large number of dimensional requirements. For example, the dimensional specifications of an automotive gearbox call for the satisfaction of some 1800 requirements [1]. Each requirement represents a Dimensioning and Tolerancing (D\&T) problem, and finding their solutions without a structured methodology is difficult and cumbersome. The task is exacerbated by the fact that traditionally only the designer has tackled the problem. These requirements instigate from life cycle issues of a product such as function, manufacturing, assembly, inspection, testing, installation, service and maintenance. It is impossible for a single person to be knowledgeable of, or an expert in all the areas concerned; but those who work full-time in a discipline can assist by providing their expert advice. To overcome the interdisciplinary nature of the problem the Concurrent Engineering (CE) approach has been proposed by a number of researchers [2-4].

However, for the successful implementation of D\&T in a CE environment, appropriate tools are needed. The development of such a tool is the main objective of this research. An effective tool, used in a CE environment, will enable the members of a product development team to determine the values of dimensions and tolerances by satisfying all the requirements of a product. Recognising that in today's engineering design environment CE can only be implemented by means of computer-based systems [5], the proposed methodology will be developed with its future computer-based applications in mind.

Over the years an enormous amount of research has been published on D\&T; comprehensive treatments of the topic can be found in [6,7]. Most research efforts have concentrated on finding the solution for dimensional requirements on an individual basis. In recent years, a number of tolerance analysis software packages [8-10] have been released commercially, but these have not resolved the problem either. To the best of the author's knowledge, none of the commercially available software includes any strategy for handling the D\&T problems of a product as a whole, or even any strategy for solving coupled functional requirements, i.e. when 
two or more functional requirements are related to each other. In this paper, an attempt has been made to develop a comprehensive solution strategy for the D\&T problems of a product by considering all the requirements simultaneously.

In [11] a methodology was developed for representing D\&T problems of a product in matrix form; this is known as a Dimensional Requirements/ Dimensions (DR/D) matrix. The purpose of this graphical representation is to provide a total picture of a product's D\&T problems. This enables the CE team to simultaneously consider all controllable variables, such as dimensions, tolerances, and proposed manufacturing processes. In this paper, a comprehensive solution strategy for a DR/D matrix is presented. The outcome of this exercise will be the dimensional specifications of a product, which will represent the best compromise between all of its requirements. This is an iterative procedure and a DR/D matrix will be used as a platform for storing and cross-checking the results after each iteration.

Various well-known strategies for determining the functional dimensions and tolerances of a product have been incorporated into the solution strategy. Many of these strategies are based on the Basic Principles for Dimensional Analysis of Engineering published soon after the Second World War by the "Inter-Service Committee for Dimensioning and Tolerancing of Drawings" in the United Kingdom [12]. To find a solution, this paper assembled all these strategies into one package; the goal of which is to provide a structured methodology to determine the functional dimensions and tolerances of a product in the context of the matrix format presented in [11].

\section{Proposed Solution Strategy}

The proposed solution strategy is illustrated in Figure 1. The strategy begins with a complete DR/D matrix (1). First, it is necessary to separate the D\&T problems represented in the DR/D matrix into a number of groups (2) according to the interrelationships between the functional equations, each group can then be solved individually (3). These groups are further classified into two types (4): (i) where 
the number of functional equations is one (i.e., the group consists of one independent functional equation only) and (ii) where the number of functional equations is more than one (i.e., the group consists of a number of coupled functional equations). Independent functional equations are unrelated; therefore, they can be solved individually (5). An additional strategy is required to determine the optimum solution order for solving coupled functional equations (6). Each functional equation in the group can then be solved one-by-one (7) and the values of dimensions and tolerances solved in one functional equation can be considered as non-negotiable in the solutions to subsequent functional equations. After the solution of each functional equation is found, the solution results are crosschecked and then stored in the DR/D matrix. (8). A solved DR/D matrix (9) will provide the values of dimensions and tolerances initially represented by the symbol $X$, which indicates all the relationships represented in the DR/D matrix.

Figure 1: The Proposed Solution Strategy.

To solve the different types of D\&T problems common to most engineering designs, a solution library should be built (10). To solve an individual functional equation, the solution procedure stored in the solution library can be applied to that particular problem. The solution library would work with a generic tolerance allocation strategy (11) and a number of additional cost minimization strategies. (12). It would also be useful to build a database containing all data necessary for solving the $\mathrm{DR} / \mathrm{D}$ matrix 13 , such as a process capability database for tolerance allocation, a preferred sizes table, a preferred fit table, and any other data that would contribute to additional cost minimization. The main aspects of the proposed solution strategy are explained in the following sub-sections.

\subsection{Strategy for Grouping Functional Equations}

As the number of functional equations grows, the management of the DR/D matrix becomes more difficult, ultimately slowing down the solution process. To 
increase the efficiency of the solution search, the grouping of related functional equations allows the $\mathrm{CE}$ team to concentrate on a particular area in the DR/D matrix without losing sight of the overall picture. This grouping would be based on the inter-relationships between the functional equations through common variables.

A simple algorithm was developed for separating D\&T problems within the DR/D matrix. This algorithm is explained by the example illustrated in Figure 2, which is a simplified DR/D matrix for the gear pump design example introduced in [11]. First, the number of $X$ terms occurring in each column is counted, and this total is entered in place of $X$. This represents the number of requirements that are related to each other through a particular dimension (first matrix in Figure 3). Then, for each dimensional requirement, entries are found in each row. Next, the dimensional requirements in which no entry is greater than one are identified (DR08, DR16, DR18, DR19, and DR21). These are the independent requirements and are numbered as Group Numbers 1 through 5. After considering a relationship, a tick symbol $(\sqrt{ })$ is entered in place of this number.

Figure 2: The Simplified DR/D Matrix.

Then, a requirement with a number greater than one is selected along the row it represents. This is DR01, as shown in the second matrix in Figure 3. Next, a dimension whose number is greater than one (L61) is identified. By moving down the column for dimension L61, the dimensions related to DR01 through dimension L61 are identified (i.e. DR02) and considered as elements of a new group (i.e., Group No 6). As the relationships between requirements through dimension L61 are taken into account, tick symbols are entered in those places and the next dimension (L81) is checked for any new relationship. After checking all the dimensions for relationships to one requirement (DR01), the related requirements (DR02) are checked in a similar fashion (see second matrix, Figure 3). After reviewing all the dimensions and all the requirements, some dimensions may still have a number other than zero, and a new group is then formed, and the process is repeated. The final outcome of this grouping is illustrated in Figure 4. 
Figure 3: Separating D\&T Problems Represented in DR/D Matrix.

Figure 4: DR/D Matrix Grouping Results.

\subsection{Strategy for Finding an Optimum Solution Order for Coupled Functional Equations}

When solving a group of coupled functional equations, the target values for all the functional equations involved have to be satisfied simultaneously. Theoretically, this process can commence at any point (i.e., in any order). Gradually, the optimization algorithm will lead toward the optimum solution through a number of iterations. However, this can be reduced by selecting a favourable starting point (i.e., an optimum solution order). From this point of view, a strategy for finding an optimum solution order is most desirable.

In the literature, very little research has been reported on strategies for solving coupled functional equations. Fortini [13] and Bjørke [14] applied allocation via the difficulty (complexity) factors strategy for solving coupled functional equations. Bennett and Gupta [15] successfully applied the Lagrange multiplier methodology for solving coupled functional equations. Strategies developed by Ostwald and Huang [16] and Lee and Woo [17, 18] generate all possible combinations of available manufacturing processes, and decisions are made on that basis. Recently, Islam [19] proposed a collection of new strategies for finding an optimum solution order which, among other factors, takes into account the number of functional equations involved, and the nature of their interrelationships. These strategies have been incorporated into a comprehensive solution strategy presented in this paper. The purpose of selecting an optimum solution is to reduce the dependencies between dimensional requirements, especially avoiding circular dependencies while searching for a solution.

The application of these strategies is shown by finding an optimum solution order for a hypothetical group of dimensional requirements. In Figure 5, the problem is first written in a simplified DR/D matrix format (1) and then solved manually, without selecting any particular solution order. The order is chosen 
arbitrarily and happens to be the order in which the dimensional requirements are listed. If the functional equations are solved independently, then seven decisions have to be made (2). From Figure 5, it can be seen that, as the coupled functional equations are solved, the number of choices decreases gradually, and decisions made in earlier solutions restrict the options in subsequent equations. For example, when DR05 is solved as part of a group of coupled functional equations, (3) the solution results decrease the remaining choices to be made from five to two. Parameters will enable the monitoring of this restricting effect.

Figure 5: Solution Choice Reduces as Coupled Functional Equations are Solved.

During the solution of DR05, the total number of variables solved $(T)$ is two. Both are coupled variables. Therefore, the number of coupled variables $(C)$ solved is two, and the number of independent variables solved $(I)$ is zero. The number of restrictions placed on the system $(R)$ is three. These parameters, calculated for each stage of the solution (3) - (5), are shown in table form in (6). All the possible combinations of solution sequences are generated, and T, C, $R$ and $I$ are calculated in each step. The results are given in Figure 6. From the above results it can be seen that, for some options (e.g., Option No 4), at some stage, all the variables are already solved, and nothing is being solved during that step. This means that, if Option No 4 is followed, the target value for DR05 would not be considered in the solution search. This is undesirable and, if possible, these options should be discarded. The first strategy is to avoid situations where nothing is being solved. To avoid this situation, look for a zero in column $T$ which indicates that nothing has been solved in that stage.

Figure 6: Steps Involved in Finding an Optimum Solution Order for a Group of Functional Equations.

If a decision cannot be made by application of the first strategy, then the second strategy should be applied. The second strategy is to minimize the 
restricting effect of coupled variables. To apply this strategy, the values in column $R$, starting with row one, are examined for the solution(s) with the minimum value of $R$. Option No. 3 has the minimum value in column $R$, row one. Therefore, Option No. 3 is selected as the best option. In cases where more than one solution has the same minimum value, then the next row is examined and a solution found with the minimum value for that row. If more than one sequence has the same minimum value then the process is repeated until all the rows have been considered.

If the decision cannot be made on the basis of the second strategy, then the third strategy is applied. It is based on the observation that those functional equations with a greater number of variables are easier to solve. This can be explained by the fact that tolerance allocation is an economic trade-off, and the greater the number of variables in a functional equation, the greater the flexibility. The third strategy is: a functional equation with the lowest number of independent variables will get preference over functional equations with a greater number of independent variables. This strategy can be applied by considering values in column I. This is accomplished by choosing the solution with the minimum value in row one. If more than one solution has the same minimum value, then consider the next row and find the solution with the minimum value (for that row).

The above strategy will not work for a group of coupled equations having more than one equation with all coupled variables. In those cases, the solution can proceed in any order. However, there is a way around this situation by uncoupling the equations, which can be achieved by considering a coupled dimension as a known dimension.

\subsection{Generic Tolerance Allocation Strategy}

This paper deals with the tolerance allocation problem, which involves distribution or allocation of the available assembly tolerance among the component parts of the assembly. Mathematically, there are an infinite number of combinations of individual tolerance values which satisfy each functional equation, yet some solutions are better than others. The purpose of a tolerance 
allocation is to find the best possible combination of individual functional tolerances. The chosen values have to satisfy all product requirements, such as function, manufacturing, assembly, and inspection. Furthermore, the chosen values should also satisfy the overall objective of any manufacturing task; i.e., to supply a product that maximizes customer satisfaction at a minimum cost.

Over the last fifty years, several tolerance allocation strategies have been proposed, and cost reduction has been the focus of most of these strategies. The existing cost reduction strategies can be grouped into two categories: (i) strategies which indirectly lead to cost reduction and (ii) strategies that attempt to explicitly minimize costs.

In indirect cost reduction strategies, a factor is chosen which is believed to correlate to both costs and tolerances; subsequently, tolerances are allocated in proportion to this factor. These strategies provide rough estimates of tolerance values for the designer. They are simple, do not need a great deal of manufacturing data, and can be applied manually. Examples of indirect cost reduction strategies are: allocation by proportional scaling [20], allocation by constant precision factors [13], allocation by difficulty factors [13, 14], and allocation by process capability [20]. Farmer [21] proposed an interesting variation of allocation via the process capability strategy by incorporating ideas from the allocation through a difficulty factors strategy. His method involves determining the maximum and the minimum tolerance values achievable by a manufacturing process using its process capability data. Then, the achievable tolerance is determined considering a number of difficulty factors.

Direct cost reduction strategies consist of two basic steps: (i) development of a cost-tolerance model and (ii) application of a suitable solution method to find the values of tolerances when the manufacturing cost is at a minimum. These strategies are further divided into two types: (i) a continuous cost-tolerance model and (ii) a discrete cost-tolerance model. In a continuous cost-tolerance model, an algebraic relationship is established between tolerance and cost, typically using empirical data through regression analysis. A typical cost-tolerance relationship is illustrated in Figure 7. Various functions have been proposed to represent a cost- 
tolerance relationship, such as, reciprocal [20, 22], reciprocal squared [23], reciprocal power [24], and exponential [25]. Numerous methods such as Lagrange multiplier [14, 20, 25], linear programming [14], and nonlinear programming [22] have been proposed for optimizing the tolerance-cost relationship. The main drawbacks of these strategies are: there is no theoretical basis for the tolerancecost relationship, and the required cost data is not available, especially at the early design stage. Discrete cost-tolerance models $[17,26]$ are promising; however, the question of the availability of reliable data remains.

Figure 7: Typical Cost-Tolerance Relationship.

A number of researchers have based their tolerance allocation on minimizing quality loss and/or productivity loss, which is the sum of quality loss and production cost. The representative works include Söderberg [27, 28], Choi and Park [29], and Fathi et al. [30]. However, these strategies require production cost data as well as replacement/repair cost data, which is often not available at the early design stage.

In addition, there are many other tolerance allocation strategies that employ relatively new solution techniques, such as: expert system [31], neural network [32], genetic algorithm [33], interval analysis [34], process capability analysis [35], particle swarm optimization [36], and tree topology [37]. It is interesting to note that, although many new techniques have appeared in the past fifty years, the basic costtolerance models have not changed significantly. For example, recently published papers [35 - 37] still apply cost models introduced in the mid-1970s.

Since the introduction of VSA in 1982 by Variation Systems Analysis Inc. [38], many other D\&T software packages have come onto the market. Examples of currently available D\&T packages are: Vis VSA (previously known as VSA) from SIEMENS [8], CETOL (previously known as TI/TOL) from Sigmetrix [9], DCS from Dimensional Control Systems [10], Mechanical Advantage from Cognition Corporation [39], and Analytix from Saltire Software [40]. The emphasis of these packages has been on tolerance analysis and, therefore, they are not very helpful in solving tolerance allocation problems. 
This paper utilizes a tolerance allocation strategy which is simple and practical. It is suitable for a CE environment and is based on a variation of the tolerance allocation by process capability model proposed by Farmer [21]. It employs the Guided Iteration Methodology as a problem-solving tool which follows four basic steps: (i) formulation the problem; (ii) generating alternative solutions; (iii) evaluating alternatives; and (iv) guided redesign [41]. A flow diagram depicting the generic tolerance allocation strategy is given in Figure 8, and its main features are presented below. Details of the proposed strategy can be found in [42].

Figure 8: Flow Diagram of Generic Tolerance Allocation Strategy.

In the beginning, the CE team considers the production of each part and proposes the manufacturing processes most suitable and least costly to manufacture each feature. Although only the finishing process will be selected for further analysis, the CE team will decide on a mini process plan. The manufacturing department's staff is usually familiar with the way a feature can be produced and are experienced in judging the relative costs and the achievable tolerances. This knowledge provides an excellent starting point for the proposed strategy even though the process selection is an iterative one, and the initial choice may have to be modified several times.

The next step is to find achievable process capability tolerances under real conditions for each dimension and proposed manufacturing process. The CE team may consult the process capability database and determine the maximum and minimum tolerance values achievable by a manufacturing process under average conditions. The CE team will then assess the difficulty of producing each feature by considering factors that they feel will contribute to the particular case. On the basis of this assessment, the CE team will determine the achievable tolerance under real conditions. However, if reliable data is available from the shop floor, actual data should be utilized instead of generic data.

The process capability tolerances are then enlarged by safety factors to allow for the degree of uncertainty that is introduced by the process capability data. It is 
recommended that, for an existing process, the process capability tolerance is increased by 33 percent whereas for a new process the increment should be 50 percent [43]. The CE team then selects tolerance values for each dimension based on the enlarged process capability tolerance. The idea is to keep the manufacturing cost to a minimum by selecting tolerance values that are larger than their respective process capability tolerances (see Figure 7).

The next step is to calculate the residual tolerance, which is the difference between the available assembly tolerance and the sum of all selected tolerance values. A negative value of residual tolerance will indicate that the target tolerance requirement has not been met, and consequently, some corrective actions are necessary. To remedy this situation, the CE team selects the options that have the greatest effect on residual tolerance and proposes alternative processes. After generating a number of possible solution options, the most suitable is selected on the basis of the manufacturing operation time required to produce the feature. This methodology is known as Manufacturability Rating Technique - Baseline (MRTB). After deciding which process is to be changed, the CE team recalculates the residual tolerance and evaluates the outcome. The process is repeated until an acceptable solution is found.

If solutions cannot be found through the modification of processes, then modification of design should be considered. Anther possibility is to change the assembly requirement. The proposed strategy discussed so far is based on a full interchangeable assembly strategy. However, in some cases, it may prove to be more economical to relax the stringent requirements of full interchangeable assembly and adopt other assembly strategies, such as unit assembly, selective assembly, or adjust at assembly. The selection of different assembly strategies has a profound effect on tolerance allocation; detailed treatment of this topic can be found in Bjørke [14]. 


\subsection{Development of a Solution Library for Different Types of D\&T Problems}

Different types of problems require different solution strategies. Therefore, a solution library that deals with the most common D\&T problems should be built. However, due to the diverse range of problems involved, it is not possible to include solution procedures for all types of D\&T problems in this paper. Therefore, only three types of D\&T problems are included: fitting feature problems, length dimension problems, and mixed-type problems (i.e., a combination of the length dimension problem and the fitting feature problem). The strategies for solving different types of D\&T problems reported here are primarily adapted from Gladman [44] and are modified and enhanced to suit computer applications.

Functional dimensions can be divided into two categories [14]: (i) dimensions related to fitting features and (ii) all other dimensions. Dimensions related to fitting features have a special category because, in their case, the choices of tolerances of the mating parts are restricted. They are determined by the system of limits and fits being used, basic sizes of mating parts, and type of fit. Once these variables are selected by the designer, the tolerance values are calculated using a limits and fits table similar to the one given in [45]. Then, the use of the calculated tolerance values becomes mandatory. For this reason, in the proposed methodology, the dimensions and tolerances associated with fitting feature problems have priority over other dimensions and tolerances during their allocation. Greater flexibility exists in the selection of all other functional dimensions. However, in either case, the chosen tolerance values have to satisfy the manufacturing constraints also.

\subsubsection{Strategy for Solving Fitting Feature Problems}

Fitting feature problems consist of an assembly between two parts with cylindrical features: (i) one part with an internal cylindrical feature, referred to as a hole by convention and (ii) another part with an external cylindrical feature, referred to as 
a shaft by convention. The function of a fit depends primarily on the clearance conditions, such as the minimum and maximum clearance $\left(C_{\min }, C_{\max }\right)$ and mean fit and variation $(M F \pm V A R)$ which can be calculated using the following equations [45]:

$$
\begin{array}{lll}
C_{\text {min }} & = & L D H+U D S \\
C_{\text {max }} & = & C_{\text {min }}+t_{h}+t_{s} \\
M F & = & \left(C_{\text {min }}+C_{\text {max }}\right) / 2 \\
V A R & = & \pm\left(t_{h}+t_{s}\right) / 2
\end{array}
$$

where, $L D H$ is the lower deviation for the hole, $U D S$ is the upper deviation for the shaft, $t_{h}$ is the tolerance value for the hole, and $t_{s}$ is the tolerance value for the shaft.

The solution procedure for a fitting feature is comprised of four steps: (i) selection of a nominal size; (ii) selection of a fit system; (iii) selection of the deviations for the hole and the shaft; and (iv) selection of tolerance values for the hole and the shaft. The nominal size is selected either by scaling the product design drawing or through calculations. The decision on the selection of a fit system to be used is usually based on the ease of manufacturing. The deviations and the tolerance values for the hole and the shaft are determined from the clearance conditions.

A new computer-based strategy has been developed to select fits, the details of which can be found in [46]. A flow diagram showing the solution strategy is illustrated in Figure 9. This strategy solves problems when the target values are specified in one of four forms: (i) general description, (ii) maximum and minimum clearance, (iii) mean fit and variation, and (iv) specification. The solution strategy ensures process compatibility with the fit selection by providing two options: (i) select the fit first and then select the process, or (ii) select the process first and then select the appropriate fit. The solution strategy can also handle fitting feature problems with non-negotiable dimensions (e.g., purchased parts). 
Figure 9: Flow Diagram of Fitting Feature Solution Strategy.

\subsubsection{Strategy for Solving Length Dimension Problems}

Length dimension problems consist of two or more parts and deal with the D\&T of their length features. In this type of problem, the length dimensions* of component parts and the dimensional requirement form a closed loop called a dimensional loop. In general, a functional equation of a length dimension problem has the following form:

$$
(Z \pm z)=\sum_{i=1}^{n} A_{i} S_{i}\left(X_{i} \pm x_{i}\right)
$$

where $Z$ is the dimensional requirement (basic size), $Z$ is the dimensional requirement (size tolerance), $A_{i}$ is the sign constant 1 or $-1, S_{i}$ is the sensitivity factor, $X_{i}$ is the functional dimension (basic size), and $x_{i}$ is the tolerance value.

Applying the methodology of extremes to Equation 5 it can be seen that:

$$
\begin{aligned}
& Z=\sum_{i=1}^{n} A_{i} S_{i} X_{i} \\
& Z=\sum_{i=1}^{n} S_{i} X_{i}
\end{aligned}
$$

Equation 6 is used to select basic sizes. The usual approach is to select all but one basic size, where this latter is calculated to satisfy Equation 6 . The strategy is to select as many basic sizes as possible from preferred sizes. Equation 7 is known as a tolerance equation. To allocate the individual tolerance values, the generic tolerance allocation strategy developed in sub-section 2.3 is applied. A flow diagram of the length dimension solution strategy is given in Figure 10.

\footnotetext{
* Length dimensions are usually defined by the distance between two parallel planes.
} 
Figure10: Flow Diagram of Length Dimension Solution Strategy.

\subsubsection{Strategy for Solving Mixed-Type Problems}

Fitting feature problems and length dimension problems are often combined. In this paper, these are called mixed-type problems. A length dimension problem occurs when one or more fitting feature problem is embedded within the dimension loop. In general, mixed-type problems have the following form:

$$
(Z \pm z)=\sum_{j=1}^{p}(F F)_{j}+\sum_{i=1}^{q} A_{i} S_{i}\left(X_{i} \pm x_{i}\right)
$$

where $(F F)_{j}$ is the length variations resulting from pairs of fitting features, $p$ is the number of fitting feature pairs, and $q$ is the number of length dimensions.

In fitting features, the choice of dimensions and tolerances of the mating parts are restricted; in their solution search, the proposed strategy assigns them a higher priority over others. Thus, by solving fitting features first, the mixed-type problem will be converted into a length dimension problem. After solving each fitting feature problem, the target value must be modified. For this modification, the sign of the clearance of each fitting feature has to be considered. When a clearance is negative (i.e., an interference fit) the influence of that fit on the target value of the mixed-type problem is neglected.

\subsection{Additional Cost Minimization Strategies}

The generic tolerance allocation strategy presented in sub-section 2.3 attempts to minimize tolerance production costs by selecting the appropriate tolerance values for each dimension based on process capability tolerances. However, in product realization, there are other costs involved, such as the cost of blank material, the cost of producing non-functional dimensions, and non-productive costs. Additional strategies are required to minimize these costs, and brief descriptions of them are given below. 


\subsubsection{Use of Standard Parts}

The proposed solution strategy employs the use of standard parts wherever possible. This reduces costs by decreasing the time and effort expended on producing and servicing a product. The specific objectives of this strategy are: reduction in detailed design work; economy in production and inspection costs; reduction in the amount of inventory; standardization of handling and assembly operations. The use of standard parts is also part of the Design for Manufacturability (DFM) strategy.

\subsubsection{Use of Preferred Sizes}

Preferred sizes are a mathematically-based series of sizes which provide the designer with a guide to size selection. Thus, unnecessary variations in sizes selected for dimensions are eliminated. This reduces the cost of tools and materials and makes them readily available, thereby reducing lead times. Details of preferred sizes and their selections are given in [47]. Wherever possible, a basic size should be selected from preferred sizes.

\subsubsection{Use of Preferred Fits}

The same clearance conditions for a fit can be achieved by different combinations of fundamental deviations and tolerance values. Therefore, to minimize costs, manufacturers often compile a list of fits recommended for use within the company, according to available process capabilities. These fits are known as Preferred Fits and should be selected whenever possible.

\subsubsection{Use of Preferred Tolerances}

Wherever possible, tolerance values should be selected from Preferred Tolerances to minimize manufacturing and inspection costs. Decreasing the number of tolerance values reduces the cost of supplying gauges and measuring instruments and reduces the probability of misreading them from engineering drawings. 


\subsection{Development of a Database for Solving D\&T Problems}

The proposed solution strategy requires the following data for solving D\&T problems: preferred sizes, preferred tolerances, preferred fits, limits and fits table of deviations, standard tolerances, and process capabilities. A database containing this data should be developed. The process capability data should match the process capabilities of the processes to be used. Hence, the process capability database should be updatable. To solve the three types of D\&T problems discussed above, the process capability database should have data on size tolerances. The development of an appropriate database is, in itself, an enormous task. Data adopted in this study is only indicative, is based on the capabilities of different processes under average conditions, and is gathered from different sources reported in the literature [14, 44, 48].

\section{Solved Example}

To demonstrate the usefulness of the proposed methodology, the following example has been solved. The steps involved in solving this example are described below. It must be acknowledged that due to various reasons it was not possible to form a full CE team, therefore, the reader is requested to pay attention to the methodology rather than the final solution results.

The gear pump design problem is taken from [49] which was introduced and analysed in the first paper [11]. The dimensional requirements and target values are taken from [50]. In some cases the target values are modified to demonstrate the effectiveness of the methodology. The problem consists of twenty-one dimensional requirements with a number of coupled functional equations. First, the methodology presented in [11] was applied to represent the problem in a DR/D matrix format. Then, applying the algorithm presented in sub-section 2.1, the dimensional requirements were divided into nine groups according to the inter-relationships among the variables. 
The first five dimensional requirements were independent dimensional requirements and were solved first. As these are all fitting feature problems; the solution strategy discussed in sub-section 2.4.1 was used to find the solutions. A screen print showing a fit ranking table from software based on the present methodology is given in Figure 11. In the top line of the ranking table, the entered values of $C_{\min }$ and $C_{\max }$ and/or mean fit (MF) and variations (VAR) are given, followed by all the possible combinations. It also shows whether a fit is a preferred fit.

Figure 11: Fit Ranking Table.

The solved DR/D matrix for the gear pump design example is shown in Figure 12. To solve coupled dimensional requirements, the strategy discussed in sub-section 2.2 was applied to find an optimum solution order for each group. For example, the solution order of the dimensional requirements in Group 7 was changed from DR03 $>$ DR10 $>$ DR05 $>$ DR17 (Figure 4) to DR17 > DR05 > DR10 > DR03 (Figure 12). Individual dimensional requirements were then solved using the relevant strategy, presented in sub-section 2.4.

Figure 12: Solved DR/D Matrix for the Gear Pump Design Example.

The effective capability index included in the solved DR/D matrix (Figure 12) is the parameter which represents the compatibility of a selected manufacturing process with a selected tolerance value. It is calculated using the following formula:

$$
E C_{p}=\frac{x}{P C T}
$$

where, $E C_{p}$ is the effective capability index, $x$ is the specified tolerance value, and $P C T$ is the process capability tolerance.

The main benefit of applying the proposed methodology is that it considers all of the D\&T problems of a product collectively and manages the solution 
search process systematically. As such, the effectiveness of the methodology becomes more evident when solving a DR/D matrix with a greater number of dimensional requirements and with more complicated inter-relationships. However, such problems were not chosen due to space and time constraints.

\section{Discussion}

The D\&T methodology presented in this paper utilizes the expertise of all members of a CE team to establish the dimensional specification of a product by satisfying all of its dimensional requirements concurrently. The dimensional requirements arise from life-cycle issues, such as assembly, manufacturing and inspection. Therefore, a cross-functional product development team in the CE environment will be helpful in solving D\&T problems. In addition, the D\&T can serve as a common link between all members of the CE team, thus enhancing the CE team's performance.

The main difference between the proposed solution strategy and a traditional approach is that the proposed strategy considers all requirements of a product as a cluster. Consequently, when searching for an optimal solution, each requirement and its repercussions on the whole system are considered. Another benefit of using a DR/D matrix is that all the relationships necessary for consideration are already built into the matrix, thus any violation of these relationships during solution iterations is immediately noticeable.

A number of Design for Manufacturability (DFM) strategies are integrated into this methodology. Adhering to them will ensure that a design not only achieves the functional objectives, but is also manufactured with the fewest possible difficulties in production, assembly, inspection, and servicing, and with a minimum overall cost. It is noteworthy that most of the available tolerance allocation strategies (e.g. [20]) do not include additional cost minimization strategies such as those discussed in sub-section 2.5.

The generic tolerance allocation strategy adopted in the methodology is simple and practical. It applies an informal cost optimization methodology and thereby avoids the need for cost-tolerance data. It seeks to keep the manufacturing 
costs at a minimum by selecting all tolerance values greater than their respective process capability tolerances (see Figure 7).

The solution strategy used for finding an optimum solution order is also new and unique; none of the commercially available software includes a strategy for handling coupled functional equations.

The solution of D\&T problems requires specific data which this methodology has been created to handle. Commercially available packages appear to overlook this aspect of D\&T. The tolerance values cannot be determined solely on the basis of simulation results, as commercial packages imply, because designers frequently need to refer to various databases. For example, when solving fitting feature problems access to the limits and fits table is vital.

The presented methodology has the potential to be improved. It should be pointed out that, due to the modular structure of the methodology, the replacement of any module is easy. For example, the generic tolerance allocation strategy presented here can be replaced with any other suitable strategy.

\section{Suggested Improvements and Future Work.}

Suggested improvements of the methodology:

- The methodology can be combined with parametric solid modeling. This would provide an opportunity to apply other optimization criteria, such as the mass minimization of component parts in conjunction with the determination of all the dimensions and tolerances.

- More modules could be added to the solution library to solve other types of D\&T problems not included at present, such as geometric tolerancing problems, centre distance problems and others.

- The proposed solution strategy applies the Worst Case model for tolerance accumulation. The methodology can be enhanced by including various statistical models such as Root Sum Square (RSS), Mean Shift and Monte Carlo simulation. 


\section{Concluding Remarks}

- A comprehensive solution strategy to find solutions to the D\&T problems of a product is presented. This strategy can be used to systematically derive all a product's related dimensions and tolerances from its dimensional requirements.

- A number of commonly used cost minimization strategies, such as the use of standard parts, the use of preferred sizes, the use of preferred fits, and others, have been incorporated into the proposed methodology.

- The developed methodology is suitable for computer application, which could be interfaced with a CAD package, allowing dimensional data to be imported from CAD models. The dimensions and tolerances can then be finalised with the help of the methodology, and finally, the required data can be entered into CAD models.

\section{References}

1. Anselmetti B (2006) Generation of Functional Tolerancing Based on Positioning Features, Comp-Aided Design, 38:902-919

2. Wilhem RG, Lu SCY (1992) Tolerance Synthesis to Support Concurrent Engineering, Annals of the CIRP, 41(1):197-200

3. Farmer LE (1993) Function Oriented Dimensioning Enhances Concurrent Engineering Performance, Proceedings ACME’93, IE Aust., 171-175.

4. Islam M.N (2003) Concurrent Engineering Offers the Best Solution to Tolerance Allocation Problems, New Engineer J, 6 (1):14-15.

5. O’Flynn MJ, Ahmed MM (1993) Computer-Based Concurrent Engineering System, in Parsai HR, William G (Eds), Concurrent Engineering: Contemporary Issues and Modern Design Tools, Chapman and Hall, London, 184-206.

6. Chase KW, Parkinson AR (1991) A Survey of Research in the Application of Tolerance Analysis to the Design of Mechanical Assemblies, Research in Engineering Design, 3:23 37

7. Hong YS, Chang TC (2002) A Comprehensive Review of Tolerancing Research, Int J Production Research, 40(11): 2425-2459 
8. Vis VSA (2008) SIMENS US Site, Accessed through Internet (11/4/2008), http://www.plm.automation.siemens.com/en_us/products/tecnomatix/quality/vis_vsa.shtml

9. CETOL (2008) Sigmetrix Homepage, Accessed through Internet (11/4/2008), http://www.sigmetrix.com/default.asp

10. DCS (2008) Dimensional Control Systems Homepage Accessed through Internet (11/4/2008), http://www.3dcs.com

11. Islam MN (2008) A Dimensioning and Tolerancing Methodology for Concurrent Engineering Applications I: Problem Representation, Int. J. of Advanced Manufacturing Technology, in press

12. Dimensional Analysis of Engineering Designs (1948), Vol 1, Components, Part 1, His Majesty’s Stationery Office, London

13. Fortini ET (1967) Dimensioning for Interchangeable Manufacture, Industrial Press, New York

14. Bjørke Ø (1995) Computer-Aided Tolerancing, $2^{\text {nd }}$ Edition, ASME Press, New York

15. Benett G, Gupta LC (1970) Least-Cost Tolerances - II, Int J Production Research, 8 (2): 169-181

16. Ostwald PF, Huang J (1977) A Method for Optimal Tolerance Selection, J. of Engineering for Industry, Vol. 99:58-565

17. Lee WG, Woo TC (1990) Optimum Selection of Discrete Tolerances, J. Mechanisms, Transmissions, and Automation in Design, 111: 243-251

18. Lee WG, Woo TC (1990) Tolerances: Their Analysis and Synthesis, J. of Engineering for Industry, 112:113-121

19. Islam MN (2004) A Strategy for Solving Coupled Functional Equations, Int. J. of Advanced Manufacturing Technology, 24:461-468

20. Chase KW, Greenwood WH (1988) Design Issues in Mechanical Tolerance Analysis, Manufacturing Review, 1(1):50 -59

21. Farmer LE (1999) Dimensioning and Tolerancing for Function and Economic Manufacture, Blueprint Publ., Sydney, Australia

22. Parkinson DB (1985) Assessment and Optimization of Dimensional Tolerances, ComputerAided Design, 17:191-199

23. Spotts MF (1973) Allocation of Tolerances to Minimize Cost of Assembly, J. of Engineering for Industry, 95:762-764

24. Sutherland GH, Roth B (1975) Calculation of Tolerance Based on a Minimum Cost Approach, J. of Engineering for Industry, 97:283-286

25. Speckhart FH (1972) Mechanism Design: Accounting for Manufacturing Tolerances and Costs in Function Generating Problem, J. of Engineering for Industry, 94:447-453 
26 Chase KW, Greenwood WH (1990) Least Cost Tolerance Allocation for Mechanical Assemblies with Automated Process Selection, Manufacturing Review, 3(1):49-59

27. Söderberg R (1993) Tolerance Allocation Considering Customer and Manufacturer Objectives, Advances in Design Automation -1993. 2:149-157.

28. Söderberg R (1994) Robust Design by Tolerance Allocation Considering Quality and Manufacturing Cost, Advances in Design Automation -1994, 1:219-226

29. Choi HR, Park MH (2000) Optimal Tolerance Allocation with Loss Function, J. Manufacturing Science and Engineering, 122(3):529-535

30. Fathi Y, Mittal RO, Cline JE, Martin M (1997) Alternative Manufacturing Sequences and Tolerance Build up: A point of View and a Case Study, Int. J. Prod. Res., 35(1):123-136

31. Janakiram, D, Prasad LV, Rao URK (1989) Tolerancing of Parts Using an Expert System, Int. J. of Advanced Manufacturing Technology, 4:157-167

32. Kopardekar P, Anand S (2005) Tolerance Allocation Using Neural Network, Int. J. of Advanced Manufacturing Technology, 10:269-276

33. Prabhaharan G, Asokan P, Ramesh P and Rajendran, (2004) Gentic-algorithm-based Optimal Tolerance Allocation Using a Least-Cost Model, Int. J. of Advanced Manufacturing Technology, 24: 647-660.

34. Rao S, Wu E (2005) Optimum Tolerance Allocation in Mechanical Assemblies Using an Interval Method, Engineering Optimization, 37: 237-257

35. Hsieh KL (2006) The Study of Cost-Tolerance Model by Incorporating Process Capability Index into Product Lifecycle Cost, Int. J. of Advanced Manufacturing Technology, 28: 638642.

36. Haq AN, Sivakumar, K, Saravanan R and Karthikeyan K, (2006) Particle Swarm Optimization (PSO) Alogorithm for Optimal Machining Allocation of Clutch Assembly, Int. J. of Advanced Manufacturing Technology, 27: 865-869.

37. Kumaravel P, Anand S, Ullas U, Mohanram PV (2007) Cost Optimization of Process Tolerance Allocation - A Tree Based Approach, Int. J. of Advanced Manufacturing Technology, 34: 703-713.

38. VSA-SIM User’s Reference (1997) Variation Systems Analysis, Inc., 300 Maple Park Boulevard, St. Clair Shores, MI 48081.

39. Mechanical Advantage (2008) Accessed through Internet (11/4/2008), http://www.cognition.us/products/consult_proddesc.htm

40. Analytix (2008) Saltire Software Home Page, Accessed through Internet (11/4/2008), http://www.saltire.com/ax.html

41. Dixon, J.R, Poli, C (1995) Engineering Design and Design for Manufacturing - A Structured Approach, Field Stone Publ., Massachusetts 
42. Islam MN (2007) A Practical Approach to Tolerance Allocation, Paper presented at the Int. Conf. on Engineering Technology (ICET) 2007, Kula Lumpur, December 11-13, 2007

43. Besterfield, D.H (1986) Quality Control, 2nd edition, Prentice-Hall, 1986

44. Gladman CA (1972) Geometric Analysis of Engineering Designs, $2^{\text {nd }}$ Edition, Australian Trade Publications Pty. Ltd., Sydney, Australia

45. Australian Standard (1987) AS1654, Limits and Fits for Engineering, The Standards Association of Australia, Sydney, Australia

46. Islam MN (2003) A Software Package for Solving Fitting Feature Problems, Paper presented at the 19th Int. Conference on CAD/CAM, Robotics and Factories of the Future, Kuala Lumpur, July 22-24, 249-257.

47. Australian Standard (1982) AS1122, Recommended Metric Sizes for Engineering, The Standards Association of Australia, Sydney, Australia

48. British Standards (1953) BS1916: Part 2, Limits and Fits for Engineers, British Standard Institute, London

49. Weill R (1997) Dimensioning and Tolerancing for Function, in Zhang HC (Ed.), Advanced Tolerancing Techniques, John Wiley \& Sons, 329-354

50. Islam MN (2004) A Methodology for Extracting Dimensional Requirements for a Product from Customer Needs, Int. J. of Advanced Manufacturing Technology, 23: 489-494. 


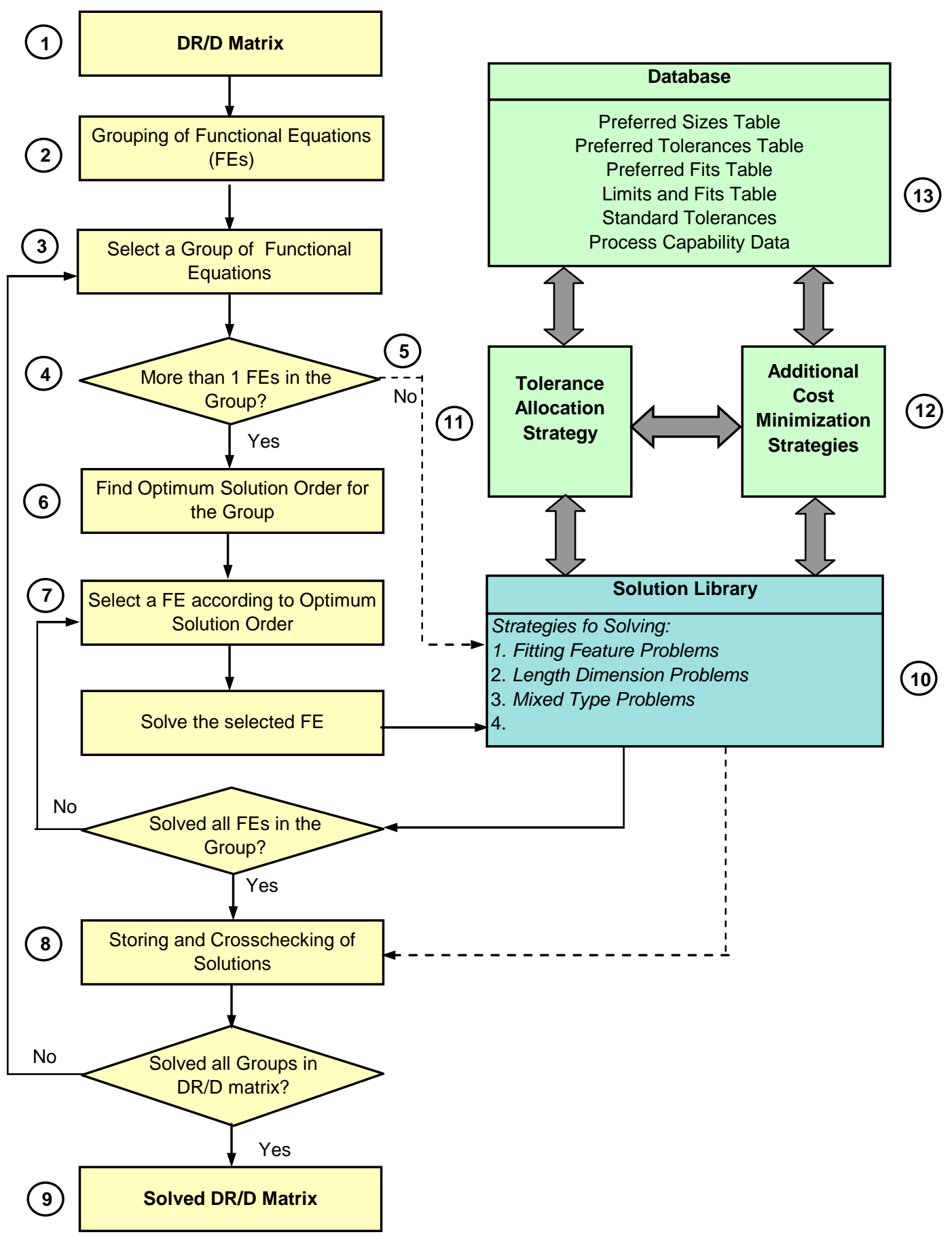

Figure 1. The Proposed Solution Strategy 


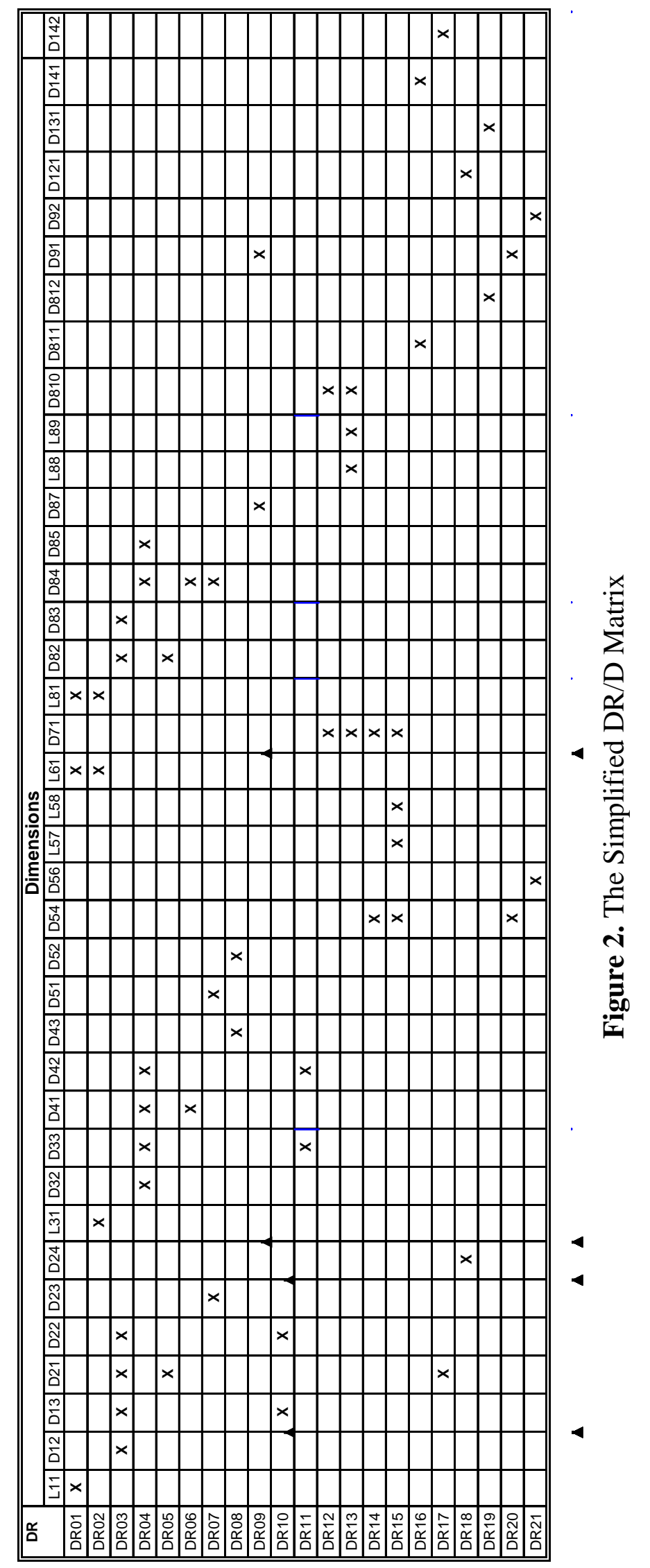



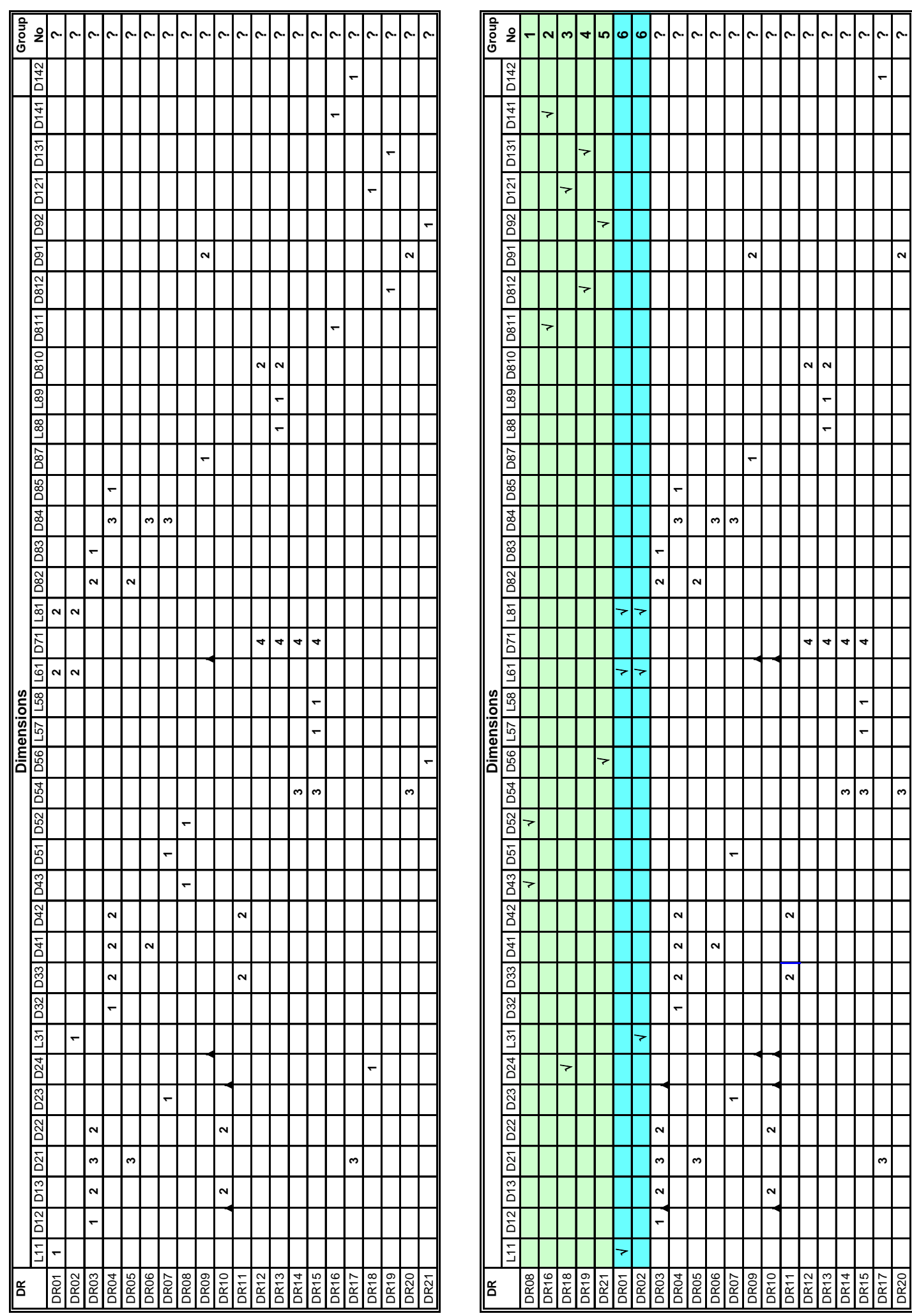

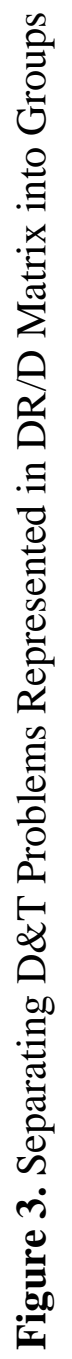




(1)

\begin{tabular}{|c|c|c|c|c|}
\hline Requirements & A & B & C & D \\
\hline DR5 & $X$ & $X$ & & \\
\hline DR6 & & $X$ & $X$ & \\
\hline DR7 & $X$ & $X$ & & $X$ \\
\hline
\end{tabular}

Initially altogether 7 decisions have to be made, which are represented by "?"

(2)

\begin{tabular}{|c|c|c|c|c|c|}
\hline Requirements & A & B & C & D & Status \\
\hline DR5 & $?$ & $?$ & & & Unsolved \\
\hline DR6 & & $?$ & $?$ & & Unsolved \\
\hline DR7 & $?$ & $?$ & & $?$ & Unsolved \\
\hline
\end{tabular}

When DR5 is solved: $T=2, C=2, R=3$, and $I=0$.

\begin{tabular}{|c|c|c|c|c|c|}
\hline Requirements & A & B & C & D & Status \\
\hline DR5 & C & C & & & Being solved \\
\hline DR6 & & R & $?$ & & Unsolved \\
\hline DR7 & R & R & & $?$ & Unsolved \\
\hline
\end{tabular}

When DR6 is solved: $T=1, C=0, R=0$, and $I=1$.

(4)

\begin{tabular}{|c|c|c|c|c|c|}
\hline Requirements & A & B & C & D & Status \\
\hline DR5 & S & S & & & Solved \\
\hline DR6 & & S & I & & Being solved \\
\hline DR7 & S & S & & $?$ & Unsolved \\
\hline
\end{tabular}

When DR7 is solved: $T=1, C=0, R=0$, and $I=1$.

(5)

\begin{tabular}{|c|c|c|c|c|c|}
\hline Requirements & A & B & C & D & Status \\
\hline DR5 & S & S & & & Solved \\
\hline DR6 & & S & S & & Solved \\
\hline DR7 & S & S & & I & Being solved \\
\hline
\end{tabular}

The outcome of the above procedure is summarised in the following matrix.

(6)

\begin{tabular}{|c|c|c|c|c|}
\hline Requirements & $\mathrm{T}$ & $\mathrm{C}$ & $\mathrm{R}$ & $\mathrm{I}$ \\
\hline DR5 & 2 & 2 & 3 & 0 \\
\hline DR6 & 1 & 0 & 0 & 1 \\
\hline DR7 & 1 & 0 & 0 & 1 \\
\hline
\end{tabular}

$T=$ Total number of variables solved

$\mathrm{C}=$ Number of coupled variables solved

$\mathrm{R}=$ Number of restrictions placed on the system

I = Number of independent variable solved.

$\mathrm{S}=$ Variable solved in previous steps.

Figure 5. Solution Choice Reduces as Coupled Functional Equations are Solved 
Application of Criteria No 1

Option No 1

\begin{tabular}{|c|c|c|c|c|}
\hline Requirements & $\mathrm{T}$ & $\mathrm{C}$ & $\mathrm{R}$ & $\mathrm{I}$ \\
\hline DR5 & 2 & 2 & 3 & 0 \\
\hline DR6 & 1 & 0 & 0 & 1 \\
\hline DR7 & 1 & 0 & 0 & 1 \\
\hline
\end{tabular}

Option No 2
\begin{tabular}{|c|c|c|c|c|}
\hline Requirements & T & C & R & I \\
\hline DR5 & 2 & 2 & 3 & 0 \\
\hline DR7 & 1 & 0 & 0 & 1 \\
\hline DR6 & 1 & 0 & 0 & 1 \\
\hline
\end{tabular}

Option No 3

\begin{tabular}{|c|c|c|c|c|}
\hline Requirements & $\mathrm{T}$ & $\mathrm{C}$ & $\mathrm{R}$ & $\mathrm{I}$ \\
\hline DR6 & 2 & 1 & 2 & 1 \\
\hline DR5 & 1 & 1 & 1 & 0 \\
\hline DR7 & 1 & 0 & 0 & 1 \\
\hline
\end{tabular}

Option No $4 \quad \boldsymbol{x}$

\begin{tabular}{|c|c|c|c|c|}
\hline Requirements & $\mathrm{T}$ & $\mathrm{C}$ & $\mathrm{R}$ & $\mathrm{I}$ \\
\hline DR6 & 2 & 1 & 2 & 1 \\
\hline DR7 & 2 & 1 & 1 & 1 \\
\hline DR5 & 0 & 0 & 0 & 0 \\
\hline
\end{tabular}

Option No $5 \quad x$

\begin{tabular}{|c|c|c|c|c|}
\hline Requirements & T & C & R & I \\
\hline DR7 & 3 & 2 & 3 & 1 \\
\hline DR5 & 0 & 0 & 0 & 0 \\
\hline DR6 & 1 & 0 & 0 & 1 \\
\hline
\end{tabular}

Option No 6
\begin{tabular}{|c|c|c|c|c|}
\hline Requirements & T & C & R & I \\
\hline DR7 & 3 & 2 & 3 & 1 \\
\hline DR6 & 1 & 0 & 0 & 1 \\
\hline DR5 & 0 & 0 & 0 & 0 \\
\hline
\end{tabular}

Discard Option No 4, 5 and 6.

\section{Application of Criteria No 2}

Option No 1

\begin{tabular}{|c|c|c|c|c|}
\hline Requirements & $\mathrm{T}$ & $\mathrm{C}$ & $\mathrm{R}$ & $\mathrm{I}$ \\
\hline DR5 & 2 & 2 & 3 & 0 \\
\hline DR6 & 1 & 0 & 0 & 1 \\
\hline DR7 & 1 & 0 & 0 & 1 \\
\hline
\end{tabular}

Option No 2
\begin{tabular}{|c|c|c|c|c|}
\hline Requirements & T & C & R & I \\
\hline DR5 & 2 & 2 & 3 & 0 \\
\hline DR7 & 1 & 0 & 0 & 1 \\
\hline DR6 & 1 & 0 & 0 & 1 \\
\hline
\end{tabular}

Option No 3

Option No 3
\begin{tabular}{|c|c|c|c|c|}
\hline Requirements & T & C & R & I \\
\hline DR6 & 2 & 1 & 2 & 1 \\
\hline DR5 & 1 & 1 & 1 & 0 \\
\hline DR7 & 1 & 0 & 0 & 1 \\
\hline
\end{tabular}

Best option is Option No 3.

Figure 6. Steps Involved in Finding an Optimum Solution Order for a Group of Functional Equations. 


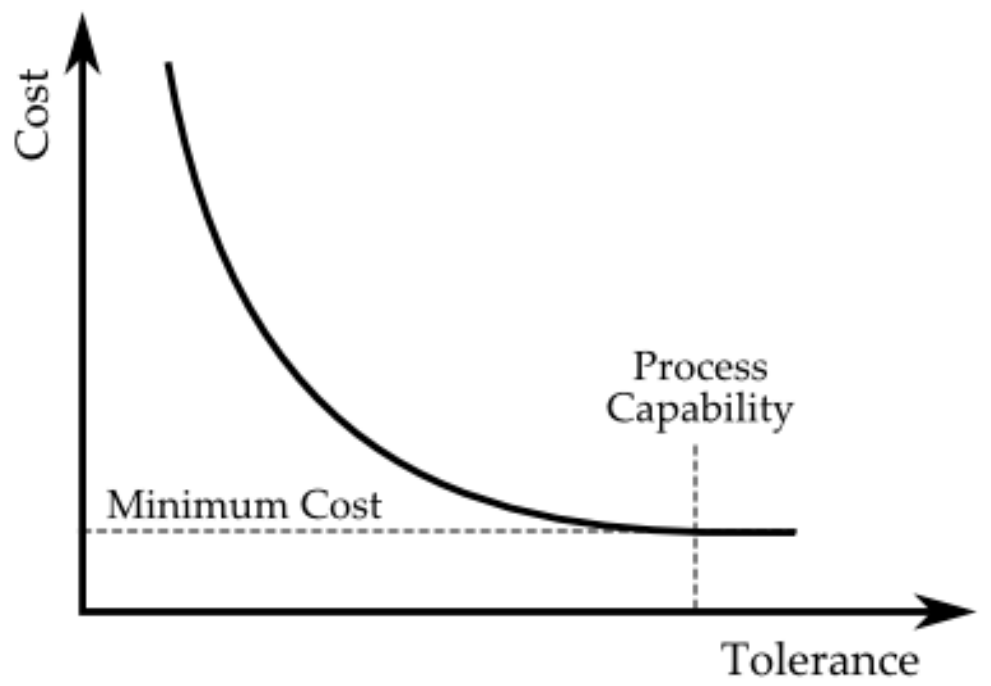

Figure 7. Typical Cost-Tolerance Relationship. 


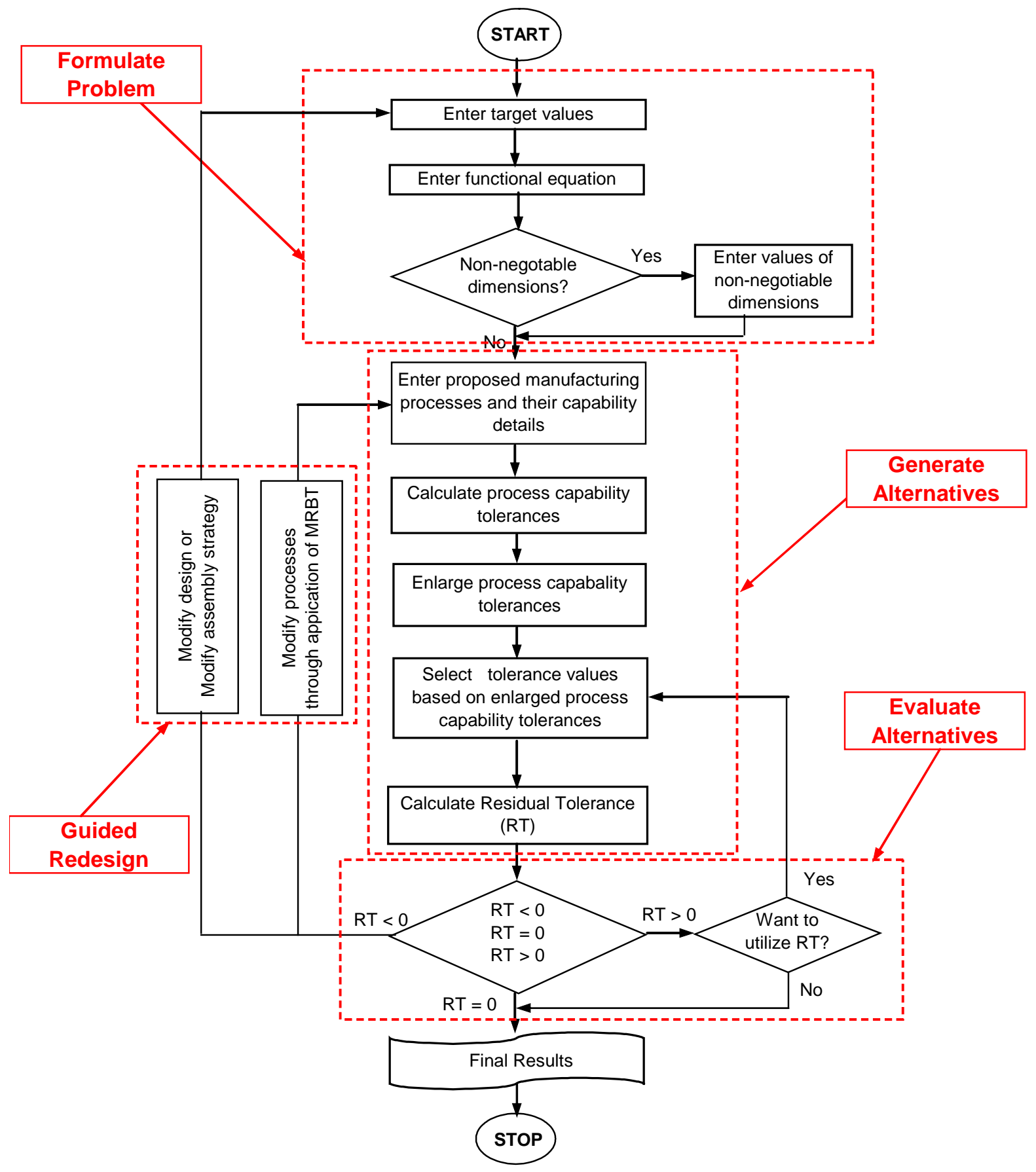

Figure 8. Flow diagram of Generic Tolerance Allocation Strategy 


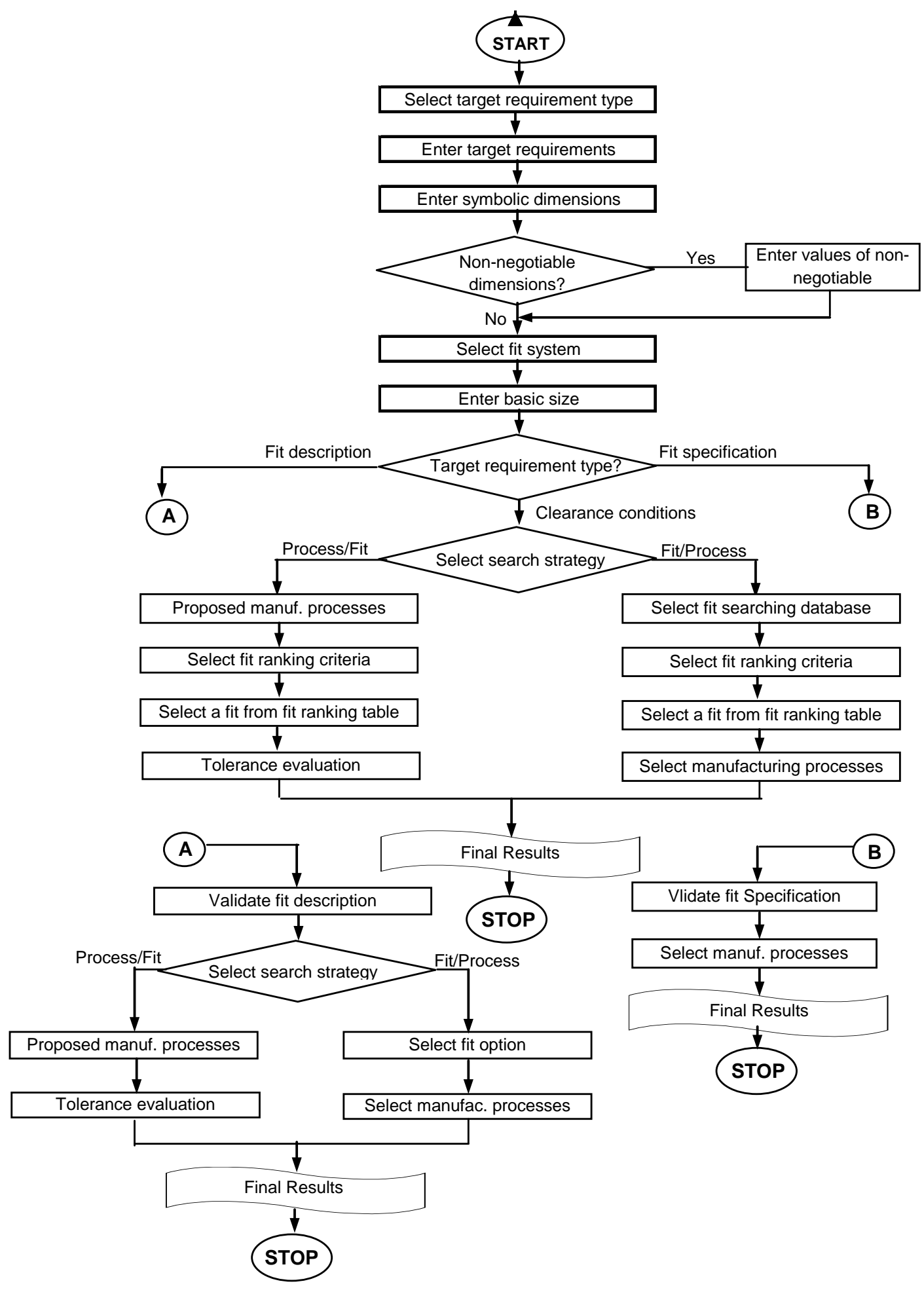

Figure 9. Flow Diagram of Fitting Feature Solution Strategy 


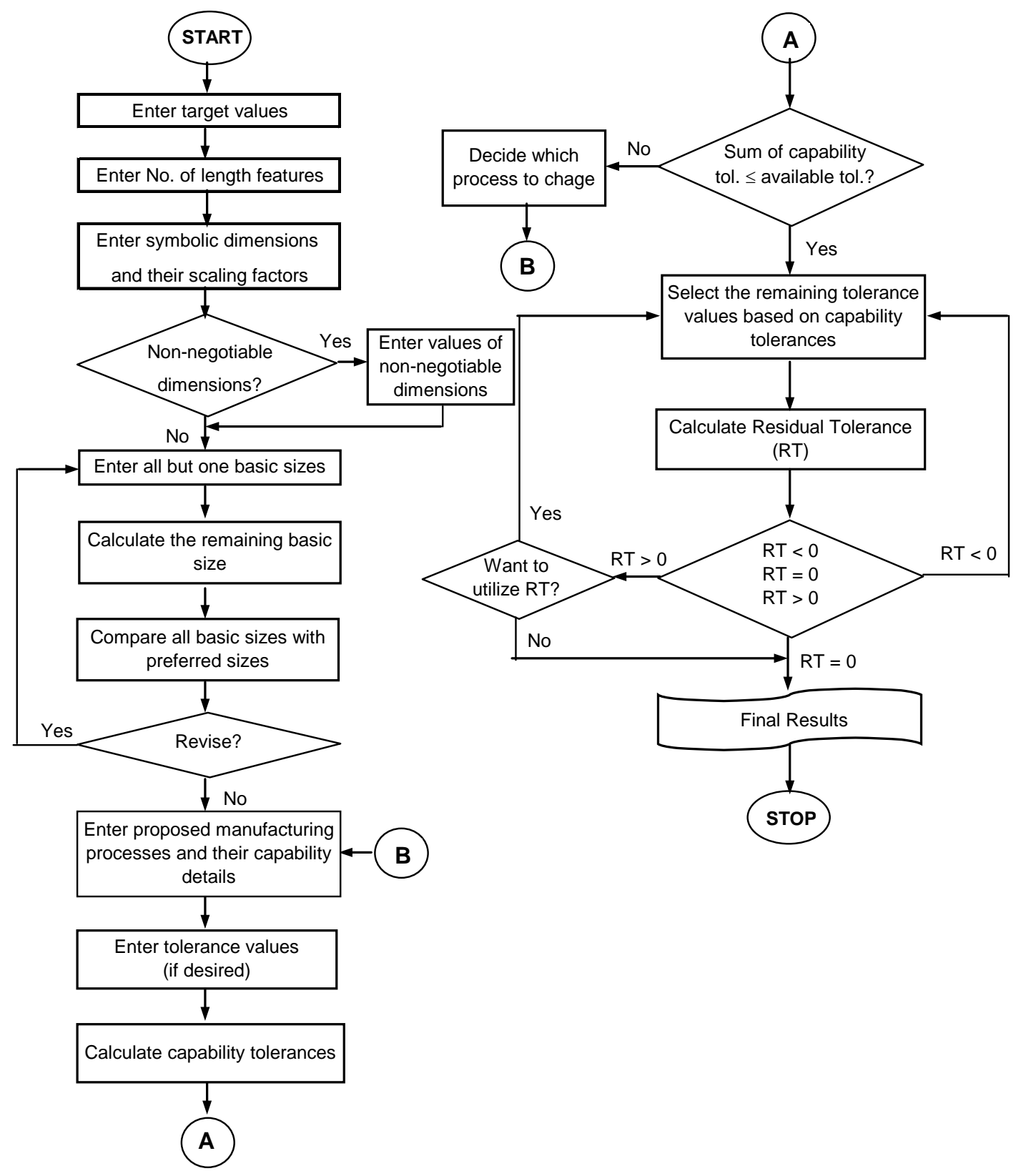

Figure 10. Flow Diagram of Length Dimension Solution Strategy 


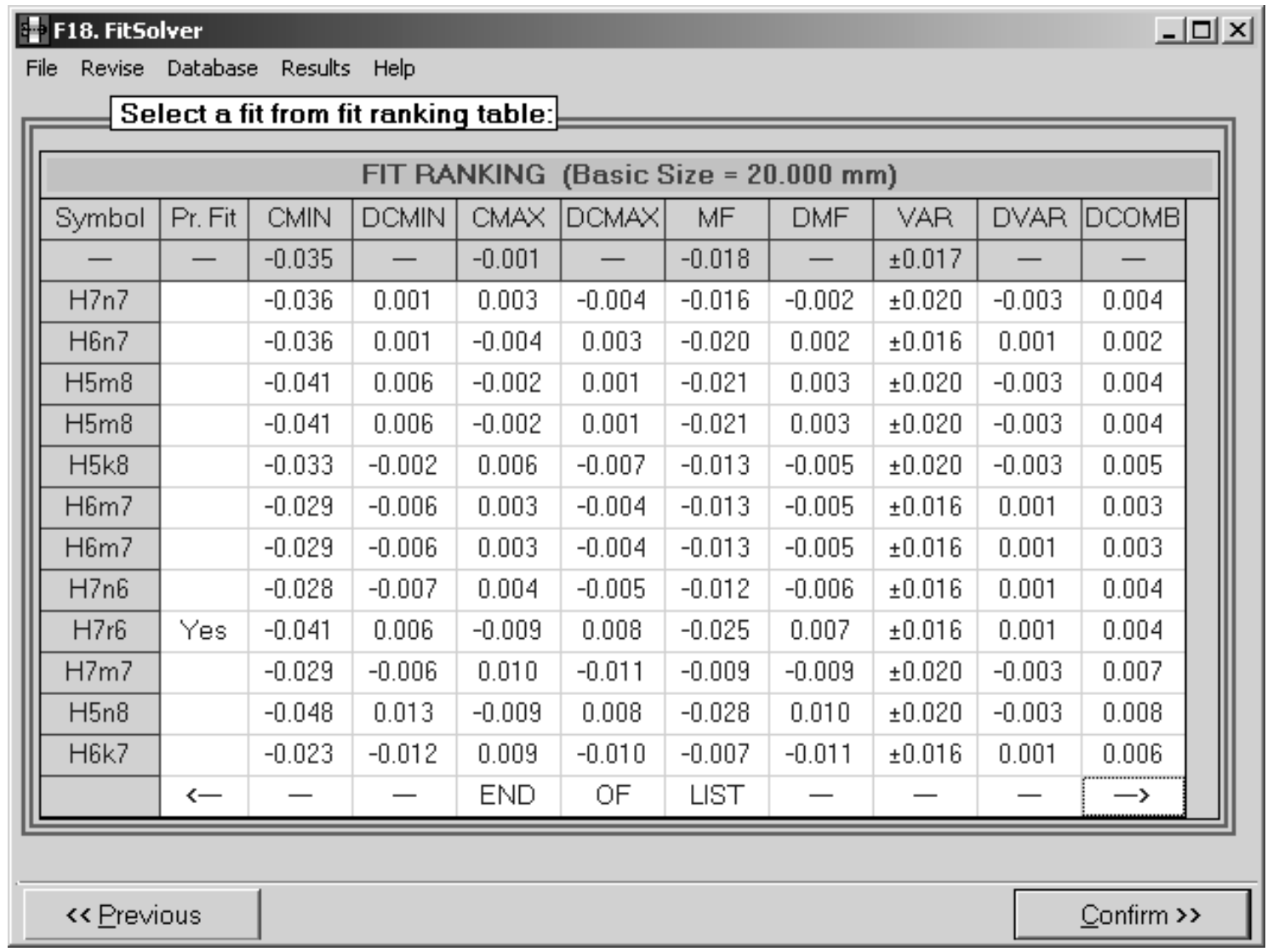

Figure 11 Fit Ranking Table 


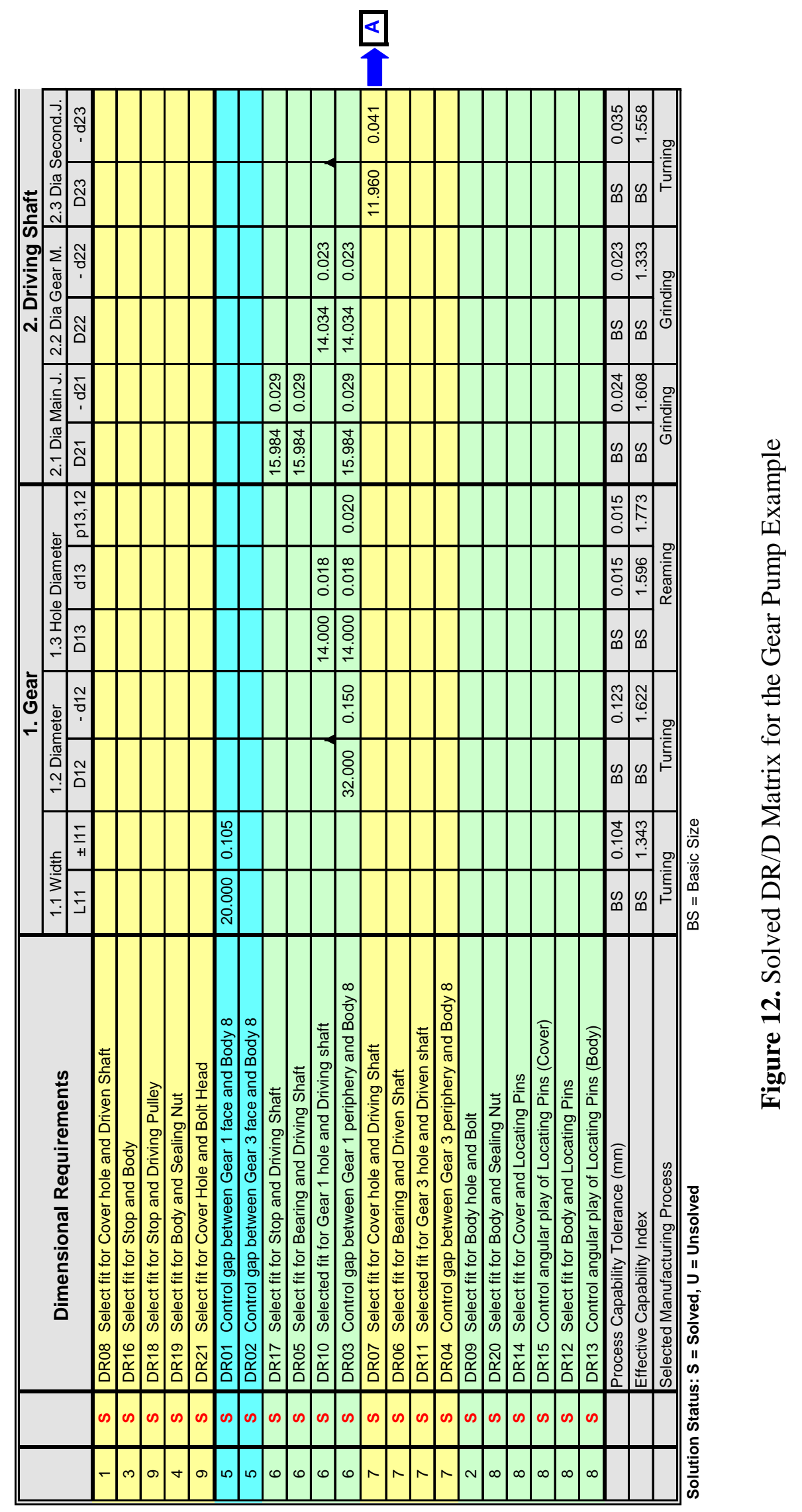




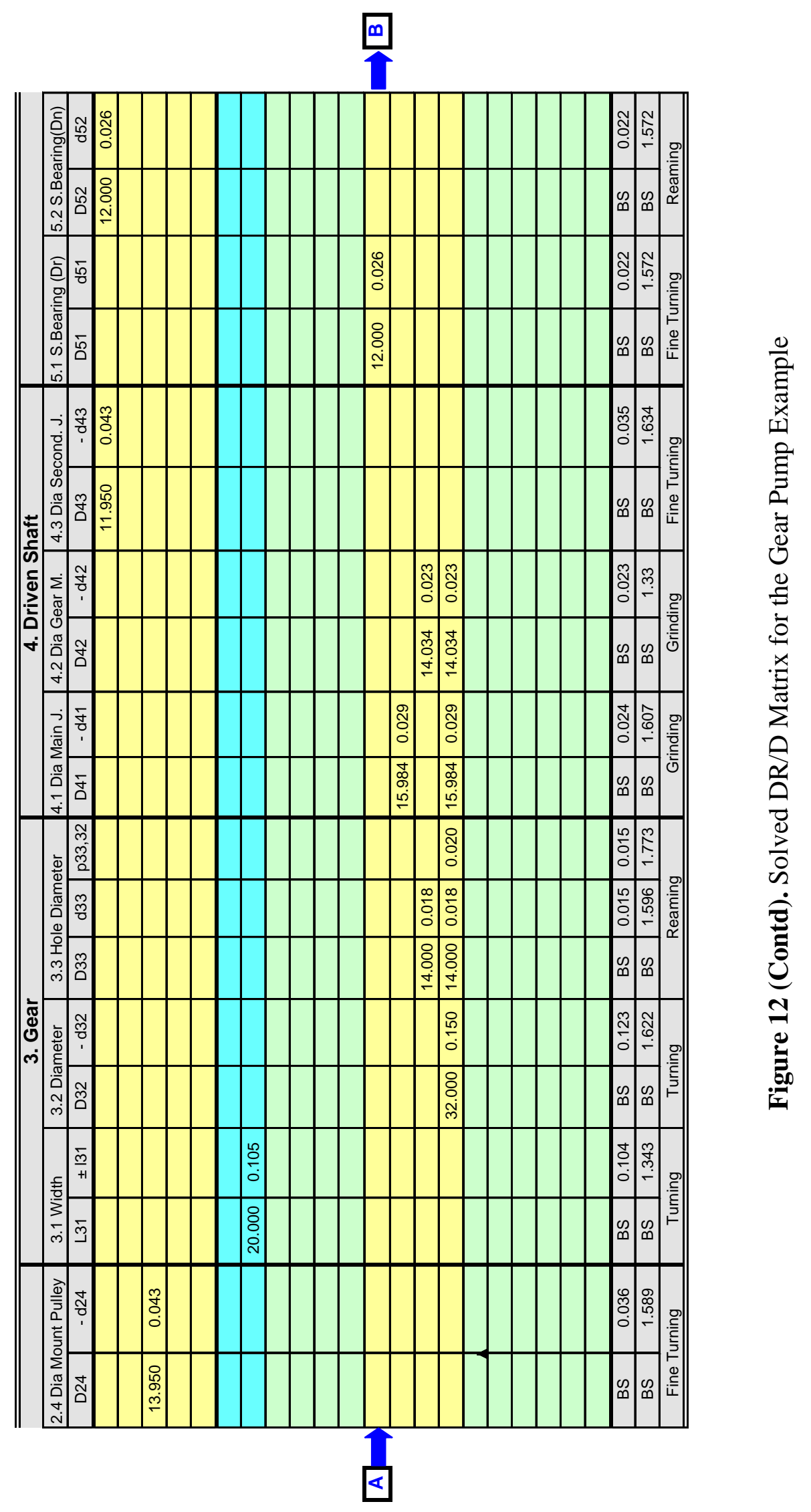




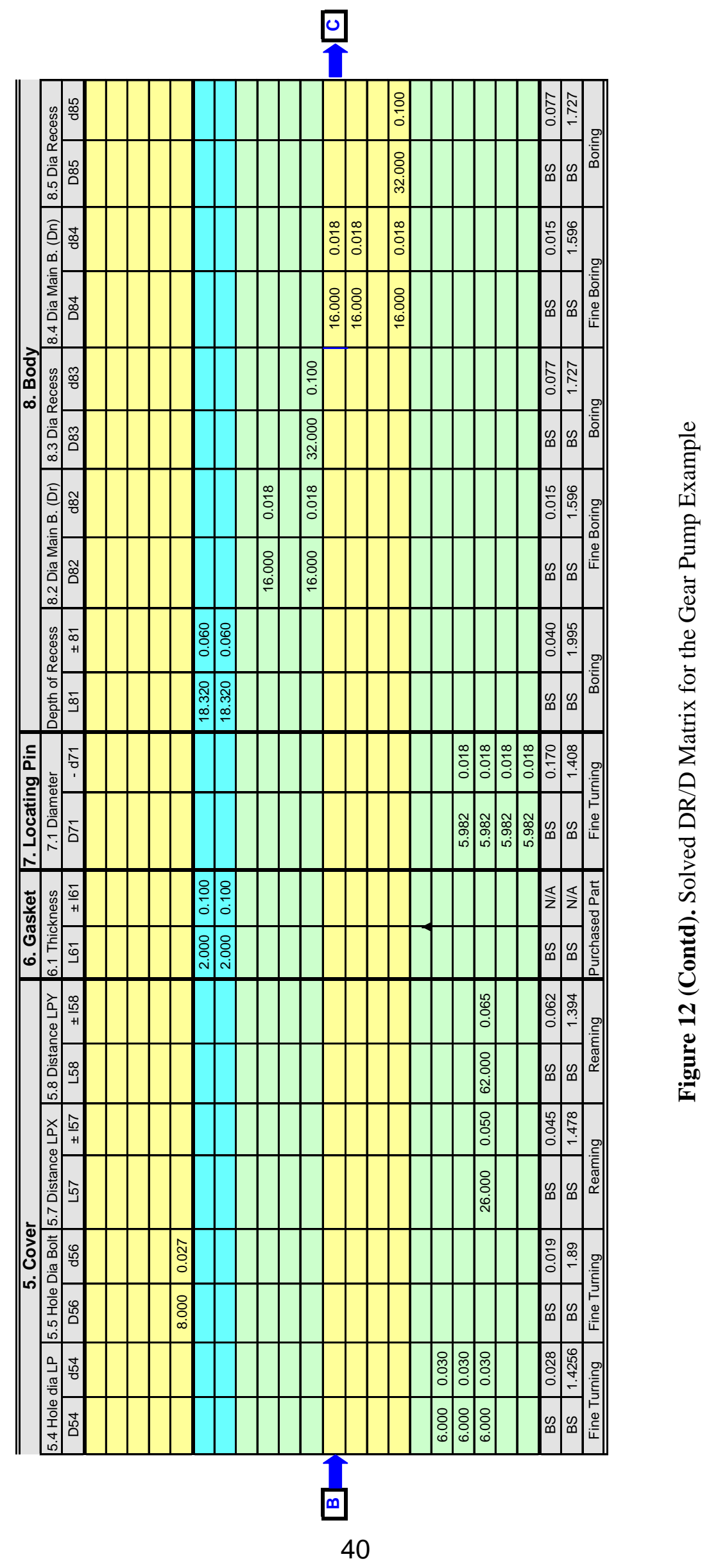




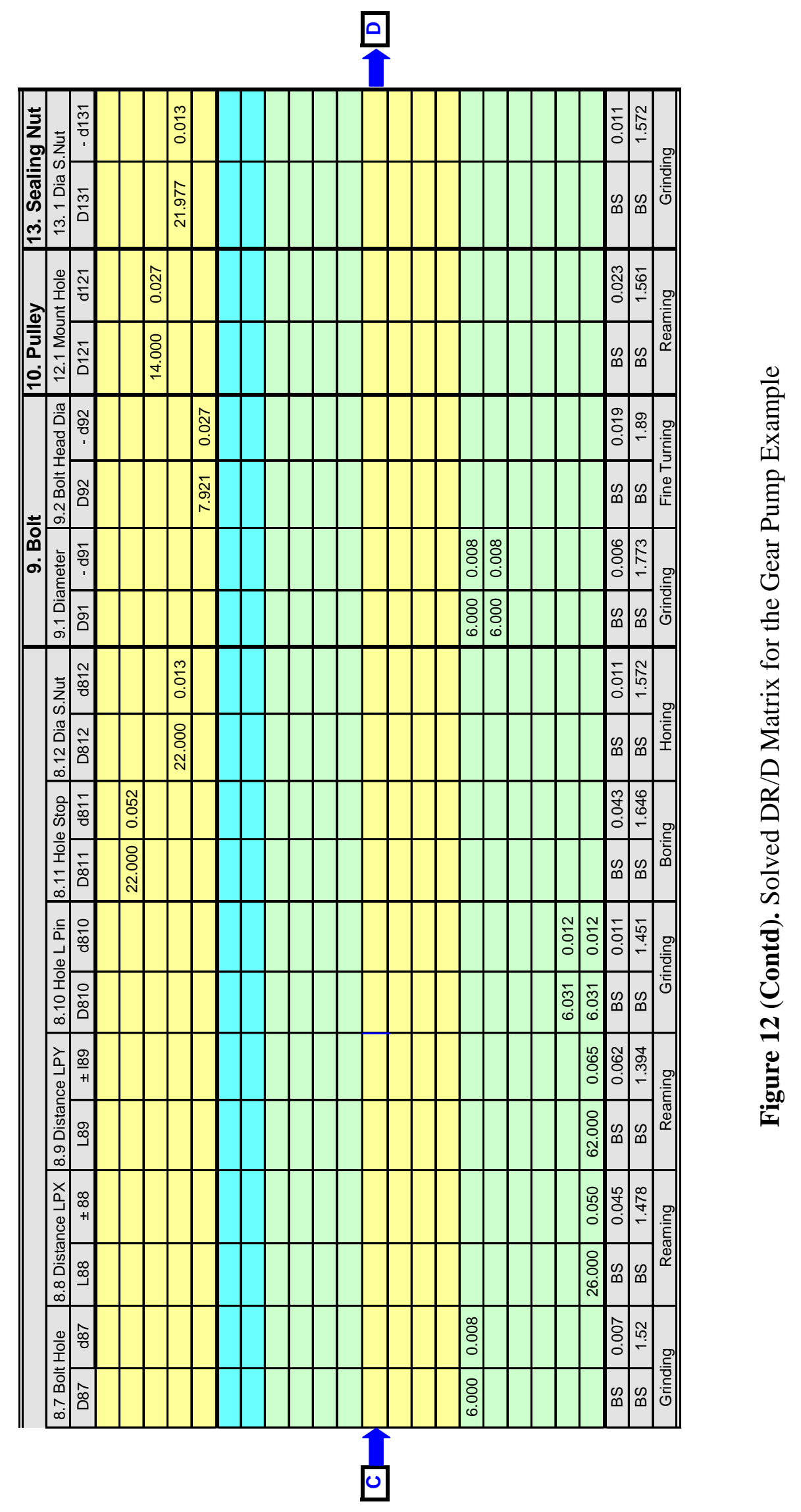




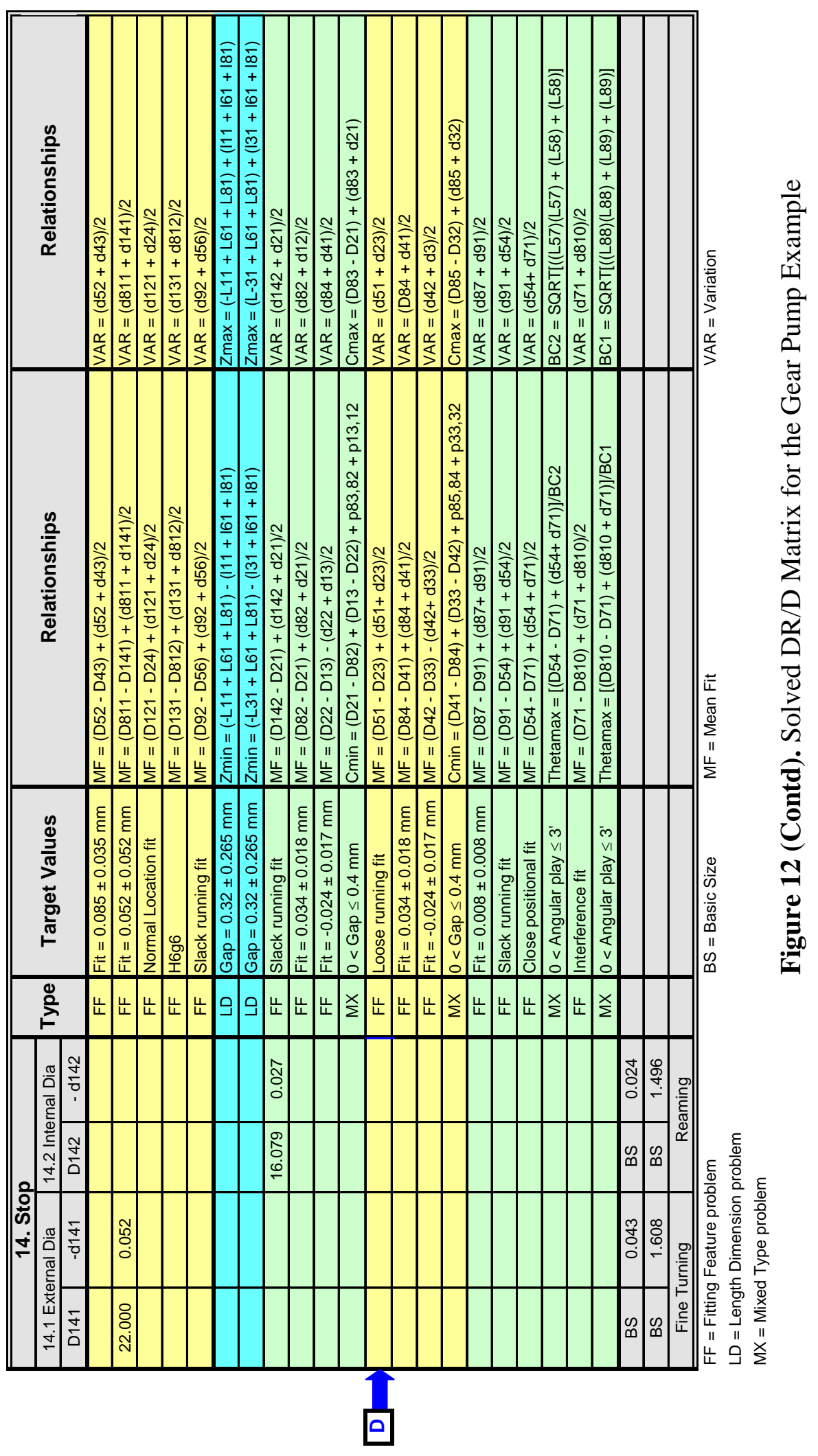

